\title{
Thai Pregnant Mobile Application: Review and Development Report
}

https://doi.org/10.3991/ijim.v15i13.23033

Rachit Pinnarong, Sorawit Siangpipop, Atichart Harncharnchai, Acrapol Nimmolrat, Orawit Thinnukool (四)

Chiang Mai University, Chiang Mai, Thailand

Orawit.tecmu.ac.th

\begin{abstract}
Background: Since health-related information for pregnant women is extremely complex and sensitive, end-users of any application are required to have the same level of knowledge as the information providers to help them to navigate between various sources of information to ascertain the reliability of contents that are often confusing. However, although there are several such applications for Thai pregnant women in the market, few were developed based on research evidence.

This study is focused on the design of a health application specifically for Thai pregnant women by extracting the explicit problems of existing applications and providing solutions to them. A design thinking methodology comprised of empathise, define, ideate, prototype and test was used as a guideline to develop a prototype app. IT experts, physical therapists and pregnant women were recruited as participants to address the problem taxonomy and obtain a solution.

The new application produced in this study with the aim of encouraging pregnant women especially for Thai women to engage in physical activity was based on research, and the input of physical therapists, IT experts and pregnant women users was able to feasibly inform the development of an acceptable and usable mobile health application for pregnant women.
\end{abstract}

Keywords - Design thinking, graphic user interface, application development, pregnant women

\section{Introduction}

\subsection{Applying the styles to an existing paper}

Smart health currently plays a significant role in humans' daily activities and provides them with several benefits. It is widely adopted and is not limited to information technology. Several types of health systems that support a variety of activities are being produced in different countries [1]. Mobile health applications or mHealth have become a tool that enables smartphone owners to lead a smart life by providing them with general information about the prevention of illness, medication, rehabilitation, etc. [2-8]. 
In terms of the use of mobile health applications, it has been reported that approximately 325,000 such applications were downloaded in 2017 [9] and the most common of these were related to primary care (41\%) and prevention (47\%) [10]. The use of these applications in Thailand corresponds to the rapid growth in the number of smartphone users [11]. However, although approximately $5 \%$ of the total number of 8,131 applications released by Thai publishers are associated with health care [12], only 38 of the 99 applications installed each month are used in practice [13].

Moreover, it has been found that most of the available health applications were not developed based on evidence from research [14], causing many of them to be useless due to poor design, low functionality or users' misunderstanding [15-17] and the functionality of some of them is not based on clinical evidence [18-19].

The above reasons correspond to the study of many researchers, who claim that developers have failed to consider users' needs in terms of functional tasks, adequate contents and large-sized text, as well as there being a mismatch between the user interface and functionality [20-22]. This is significant because the quality of any application depends on users' ability to operate it and this mainly relies on the interaction between the functionality of the app and the user interface design [23].

Despite having a limited performance, the applications that are currently available in the market are still widely used by women as a source of information and communication during pre-pregnancy, pregnancy and postnatal periods [24]. In essence, the number of different types of available pregnancy applications is growing because many pregnant and postpartum women prefer to self-manage their pregnancy based on the acquisition of information from $\mathrm{mHealth}$ and favour its incorporation into antenatal care [25].

The interest in women's health, especially in terms of physical activity, is particularly important for women during pregnancy to enhance their own health, as well as the health of the foetus. Pregnant women have described the problems with currently-available applications as lacking consistent information and advice in relation to the benefits of physical activity during pregnancy [26]. Therefore, a mobile application that provides consistent information anytime and anywhere may be the solution to these problems.

However, not all high-performance mobile health applications can function in different places [27] because language can be a barrier to the functioning of an app outside the country in which it was developed [29], rendering it useless to non-native language speakers. Meanwhile, unclear content or functions that fail to address the needs of certain groups of women, such as those in populations that are culturally and linguistically diverse, are also problematic [29].

Therefore, several researchers have identified poor design, low usability and functionality due to the lack of research of clinical operations, together with the language barrier, as the major causes of the poor performance of some smart technology. Nevertheless, despite being theoretically possible to enhance the usability, performance and quality of mobile health applications, various issues still challenge developers to design and implement a mobile health application to support pregnant women. In order to avoid these issues, the mobile application designed and developed in this study is focused on encouraging pregnant women to engage in physical activity since, according 
to research, there are just a few of these types of apps in Thailand. Although many research institutes in Thailand have tried to develop smart health applications, none of them have been adequate for use in today's smart lifestyle [30-31].

Therefore, the first research question is how to design an application that complements the modern healthcare system in the context of Thai society and the second is what functions it would need to have to support pregnant women from the perspective of health professionals and to meet the expectations of physical therapists, IT experts and pregnant users.

\section{$2 \quad$ Literature Review}

\subsection{Design thinking}

Design thinking is defined as a scientific methodology used by developers to design and produce a system with high usability based on users' requirements [32]. It has been applied to innovation in the fields of business management [33-34], information technology [35] and healthcare [20, 36-37]. This methodology consists of an iterative process of understanding users' needs, challenging various expectations, redefining problems and creating innovative solutions [38-39]. According to Thomas [32], it consists of the following 5 phases;

Phase 1: Empathise. This involves understanding users in terms of their needs and the problems that need to be solved.

Phase 2: Define. This involves identifying the core problems.

Phase 3: Ideate. This involves thinking outside the box to acquire many ideas and alternative solutions so that the problems are solved at the end of the ideate phase.

Phase 4: Prototype. This involves producing a prototype to identify the best possible solution to each of the problems stated in the first three phases.

Phase 5: Test. This involves rigorously testing the completed product using the best solutions identified in the prototype phase. Based on the results of this phase, a poor design and incomplete prototype can be improved by returning it to the previous phases.

\subsection{Usability}

A usability design is a solution that involves creating a graphical interface, which is strongly correlated to the functional design. In this study, Nielsen's 10 usability heuristics for the design of a user interface were applied as the necessary design criteria. Nielsen's 10 general heuristic principles are shown in Table 1 [40]. 
Table 1. Nielsen's 10 general heuristics

\begin{tabular}{|c|l|}
\hline No. & \multicolumn{1}{|c|}{ Suggested principles } \\
\hline 1 & Visibility of system status \\
\hline 2 & Match between system and the real world \\
\hline 3 & User control and freedom, \\
\hline 4 & Consistency and standards \\
\hline 5 & Error prevention \\
\hline 6 & Recognition rather than recall \\
\hline 7 & Flexibility and efficiency of use \\
\hline 8 & Aesthetic and minimalist design \\
\hline 9 & Help users recognise, diagnose and recover from errors \\
\hline 10 & Help and documentation \\
\hline
\end{tabular}

Moreover, a usability design must be practical and user-friendly in order to develop an effective mobile application. One of the suggested design principles is that a powerful design should be easily accessible and usable without the need of special adaptation or a specialised design [41]. According to Burgstable [42] and Moyen [43], an effective system design should be based on considering the following seven factors;

1. Equitable use: All users, regardless of their age, status and ability, should be able to benefit from the design.

2. Flexibility of use: The design should accommodate a wide range of individual preferences and abilities.

3. Simple and intuitive use: The design should be simple and easy to understand, irrespective of users' experience, knowledge and linguistic skills.

4. Perceptible information: The design should provide users with the necessary information to make the most efficient use of the system.

5. Tolerance for error: The design should minimise the possibility of negative consequences being caused by unexpected or unintended actions by users.

6. Low physical effort: The design should be proficient and comfortable to use by minimising repetitive actions or unusual body positions.

7. Size and space for approach and use: The design should be sufficiently flexible to enable users to approach, reach, manipulate and use the application, regardless of their bodily size, posture or mobility.

\subsection{Related work}

Pinem et al. [45] recently designed a mobile application for highly mobile medical staff to support universal health coverage in Indonesia's health referral system. This app was based on Schneiderman's Eight Golden Rules of interface design and evaluated by means of a usability test. The results of the test showed that the design of the first iteration was good and the second iteration's design was satisfactory.

Krongkarn et al. [46] developed a mobile application for patients' triage using a criteria-based dispatch protocol. Since the aim of this application was to enable first responders to assess patients' condition quickly, it needed to include a high-performance 
user interface; hence, its design was based on a usability test, the human-centred theory, the Eight Golden Rules of interface design, and Nielsen's Ten Heuristics.

Chaudhry et al. [17] developed a pregnancy application called MomLink, especially for low-income women in the United States. They tested it based on users' feedback and expectations and the results showed that there was room for significant improvement in designing mHealth apps for pregnant women on low incomes due to unclear icons, unmet expectations, unclear goals in designing the application's functions and a confusing layout, although these shortcomings may not be problematic for other user groups.

Smith et al. [24] designed an application to provide information to pregnant women on behalf of the Australian health service. The design technique they used involved the provision of a texting element on the screen for easier access, and the content was presented in English and Vietnamese to overcome the language barrier. They also organised the interface layout and menu management in order to increase the app's usability.

\section{$3 \quad$ Methodology}

\subsection{Experimental sample}

Purposive sampling was used to recruit the participants in this study. They consisted of five physical therapists, three IT experts and fifteen pregnant users. The physical therapists were required to have had at least three years' experience, the IT experts at least one year, and the 15 pregnant users had to be at least one month pregnant. Ethical clearance and approval for the study were obtained from the Chiang Mai University Research Ethics Committee with an exemption (CMU 63-160).

\subsection{Experimental framework}

A series of design processes and methodologies was utilised to achieve the goal of creating a mobile health application for pregnant women. Design thinking was used to identify the problems and design appropriate functions, contents and a graphical user interface. The five steps of the design thinking process applied in order to identify the tasks that needed to be accomplished and the best methods to accomplish them comprised empathise, define, ideate, prototype and prototype testing. These steps overlapped in practice and were iterated and refined based on users' feedback.

\subsection{Procedure}

Purposive sampling was used to recruit the participants in this study. They consisted of five physical therapists, three IT experts and fifteen pregnant users. The physical therapists were required to have had at least three years' experience, the IT experts at least one year, and the 15 pregnant users had to be at least one month pregnant. The 5 steps can be defined as follows;

Step 1 Empathise: The pregnancy-related apps in Google Play Store were examined in order to understand and gain an insight of users' thoughts and needs. Physical therapy, Pregnancy, Exercise, Women and Medica were the keywords used to locate these apps and the search yielded 149 apps, 100 of which were identified based on their title and description and were categorised as medical (19 apps), health (45 apps), and women 
(36 apps). The names, descriptions and functions of these apps were reviewed to identify the problems related to their functionality and usability.

Step 2 Define: Similar comments that related to each type of need were grouped together to construct a taxonomy of problems to give clarity and focus to the design. This data also indicated the frequency of use of each function, as well as the graphical user interface (colour).

Step 3 Ideate: Five physical therapists, three IT experts and fifteen pregnant users were asked to complete a questionnaire as the basis of interviews from which to devise a taxonomy of problems. The questionnaire consisted of open-ended questions in order to generate ideas for as many solutions as possible. Following a discussion, a wireframe was made on paper as a low-fidelity prototype so that the participants could validate each element. This made it easier to remove, add and edit different elements to generate an application that fulfilled users' requirements; hence, it was used as a reference in the next step.

Step 4 Prototyping: After all of the required elements had been inserted into the wireframe, the Mockingbot online prototyping tool (Mockingbot.in) was used in order to generate a prototype. This was useful for preventing software errors from occurring due to incomplete, unclear or changing requirements and it was also useful for users who may not have been able to clearly define their requirements on paper.

Step 5 Testing: The purpose of this step was to obtain feedback in relation to the usability and usefulness of the prototype from the five physical therapists, three IT experts and fifteen pregnant users. This involved creating a questionnaire that contained questions that they could answer based on a 5-point Likert scale to evaluate three aspects of users' satisfaction, namely, perceived user interface, perceived ease of use and reliability. The scores were calculated in averages and standard deviation. If the average score of a specific aspect was less than 4.5 , it was refined based on users' feedback or suggestions in a revised version, which the participants were then invited to re-evaluate.

\section{$4 \quad$ Results and Analysis}

\subsection{Pre-prototyping process (Empathise and define)}

Review of existing applications for pregnant women: The keyword search initially produced 149 smartphone-based applications. 100 applications remained after screening and were categorised into three groups: (1) 19 medical, (2) 45 health, and (3) 36 for women. According to an analysis of the information provided by the pregnant women, the essential aspects to consider were the correct posture for physical activity that is appropriate for the different stages of pregnancy and correct information from reliable sources. In terms of the problems related to functionality and usability, the content, usability and interface of the existing applications for pregnant women were found to be problematic for the following reasons: 
Pictures and descriptions of physical activity guidelines are confusing. (Content)

No caution is recommended during physiotherapy. (Content)

Each function is hard for beginners to use. (Usability)

It is difficult to follow the instructions. (Usability)

The colours and icons used in the app are not attractive. (Interface)

Inconsistent content and design pattern. (Interface)

Moreover, the study team reviewed existing apps and reached a consensus on the usage of functions and the graphical user interface (colour). The top five functions frequently used were identified as output (18\%), information provision (15\%), recorder (15\%), follow-up (10\%), and calculator $(10 \%)$; hence, these were deemed to be the essential functions in this study. Since the top five colours frequently used on the application interface were white (30\%), pink (13\%), light blue (12\%), green (11\%) and blue (9\%), they were used to create the graphical user interface in this study.

Results of interviews: The interviewees identified problems related to three main factors, namely, usability, content and the graphical user interface. Hence, the user interface was found to be the major problem with the existing apps in the market and, although the interviews were focused on different types of women's health applications, each of them was found to have an interface design that could confuse users. The mobile user interface in several apps had been created based on the developer's use of various patterns; for example, some app interfaces were covered with various colours, which tended to deflect users' focus from the main objective of the app.

The next problem was found to be the content because these applications provided information about physical activity during pregnancy based on pictures and descriptive text, which may be hard to follow. While most forms of exercise are safe, some involve positions and movements that may be uncomfortable or harmful for pregnant women. For instance, some of the postures involved rotating 45 degrees, but the direction in which to rotate was unclear from the picture in the app, which was likely to cause misunderstanding. It was also found that some of the apps did not demonstrate a suitable posture for each gestational age or recommend caution when exercising during pregnancy.

The last problem found was related to the usability of the app, which could easily be misunderstood. For example, users were required to input their personal information to the app to calculate their gestational age because specific physical postures were suitable for each gestational age. A process taxonomy of these problems was subsequently constructed as a guideline to develop a questionnaire containing open-ended questions to enable the participants to suggest some solutions. 


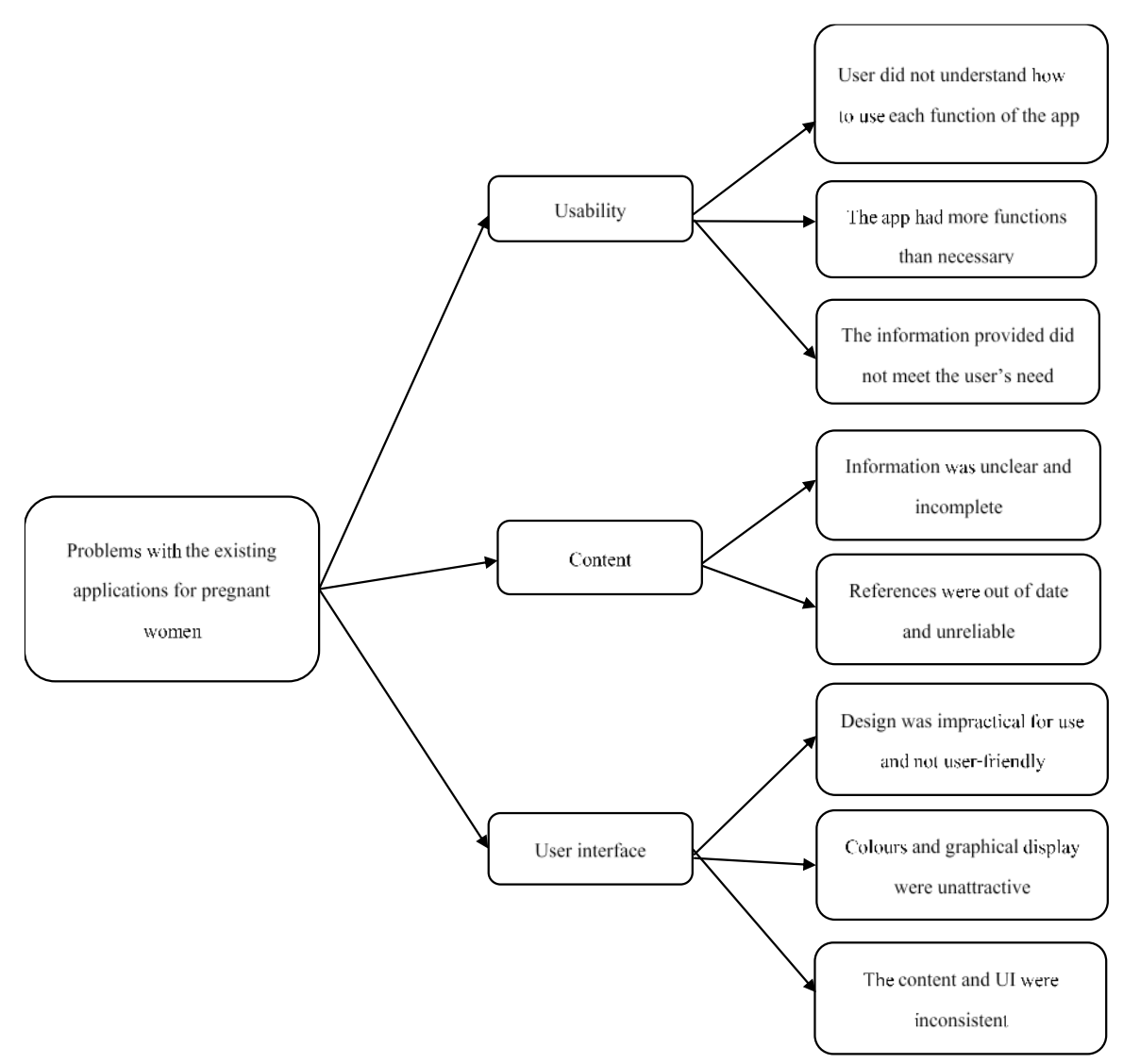

Fig. 1. Taxonomy of problems

The ideas and additional feedback of each problem provided by the experts were also summarised in a taxonomy in order to visualise them and include them in a new application. This taxonomy of problems was related to usability, and the recommended corrections are apart from efficiency and ease of use, the experts stated that the functions of the app should be considered based on suitable use and access as show in Fig 1. Hence, according to their feedback, it should have the following functions: (1) Record of user's information, (2) Follow-up of statistical results, (3) Calculator and contents displayed in an easy pattern, (4) Notifications and schedules, and (5) Menu with categories clearly separated from each other.

The taxonomy of corrections in terms of the user interface is illustrated and consists of (1) User interface design principles and Schneiderman's eight golden rules, (2) Equal use for everyone, (3) Quality assessment of functions and user interface, (4) Simple design, and (5) Colour used as a symbol of communication. The explanation of the eight golden rules of Shneiderman et al. [47] below served as a useful guide to achieve a successful design. 
Functionality (Ideate): Five functions were generated after extracting all the features and attributes, namely, media content, content provider, personal record, tracking information, and calculating information. The media content was defined as videos of physical therapy and appropriate pregnancy-related exercises and content provider was defined as the supply of pregnancy-related information, while personal record was defined as users' basic information (e.g., body weight, height, gestation age, and due date). Tracking information was defined as a diary containing self-reported information related to physical activity and exercise time to monitor the activity results. Calculating information was defined as a calculator of the gestational age and birth date of pregnant women to support the content in each trimester of pregnancy. The requirements of each function are detailed in Table 2.

Table 2. Functional requirements of the system

\begin{tabular}{|l|l|}
\hline Point of consideration & \multicolumn{1}{c|}{ Requirements } \\
\hline Media contents & $\begin{array}{l}\text { This concerns the provision of information in a video clip to enable the user to } \\
\text { clearly understand the treatment, exercise and physical therapy to strengthen the } \\
\text { pelvic floor muscles. }\end{array}$ \\
\hline Content provider & $\begin{array}{l}\text { This concerns the provision of information related to exercising muscles or any } \\
\text { necessary references to the content. }\end{array}$ \\
\hline Personal record & $\begin{array}{l}\text { This concerns the provision of a record of the user's personal information, such } \\
\text { as weight, height, etc. }\end{array}$ \\
\hline Tracking information & $\begin{array}{l}\text { This concerns the provision of a means for the user to track information such as } \\
\text { the time to exercise and the amount of time spent on each exercise. }\end{array}$ \\
\hline Calculating information & $\begin{array}{l}\text { This concerns the ability of pregnant women users to calculate their gestational } \\
\text { age and birth date. }\end{array}$ \\
\hline
\end{tabular}

The questionnaire was then used to assess the quality of the user interface from the perspective of the experts. This could clarify issues in more depth, such as the appropriateness of the information, the degree of importance of each point and which user interface should or should not be used in the app. It was expected to guarantee that the functions and elements of the user interface were consistent and would perform well together.

The wireframe shown in Fig 2. was made as a low-fidelity prototype on paper, which made it easier for the participants to visualize how the application would perform in terms of data input, graphical user interface, screen sequences, and other elements. In this phase, the wireframe enabled the physical therapists, IT experts and pregnant users to provide feedback related to the importance of the interface, functions, contents and tasks.

\subsection{Prototype}

The prototype in this study was designed and generated from the results of the preprototyping process based on using the Mockingbot online prototyping tool (Mockingbot.in). The objective of this part of the research was to improve the user interface and usability of the application, and based on the wireframe, the colours in the app were simple and the text displayed on the interface was clear and easy to read. In addition to the physical activity information, the exercise was displayed in a video tool to help 
users to understand it and hence, increase their satisfaction. It was essential that the medical contents in the application were accurate and easy for general users to understand. Therefore, providing the participants with a realistic representation of the app enabled them to interact with the prototype and formally evaluate aspects such as the visual design, content and functionality, in order to determine if they were satisfactory for the further development stage.

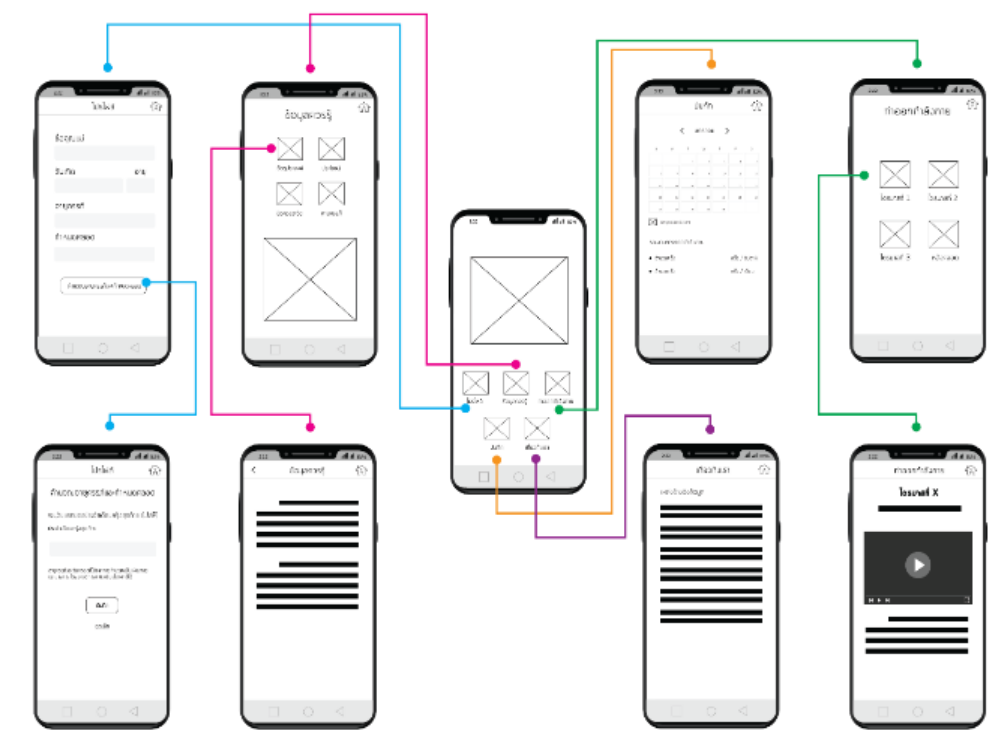

Fig 2. Application wireframe

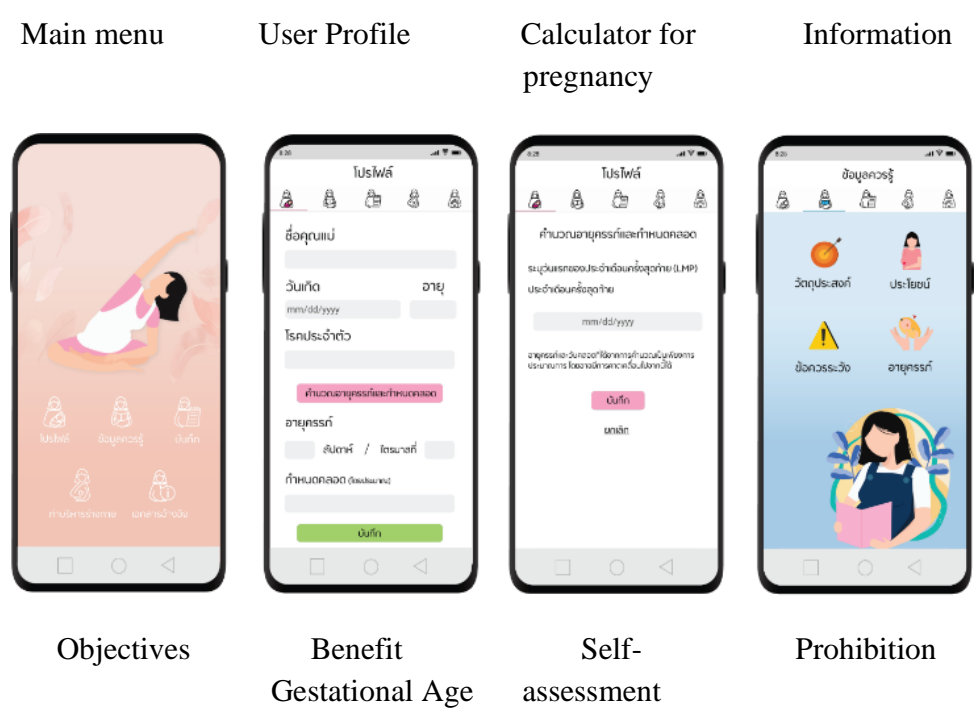




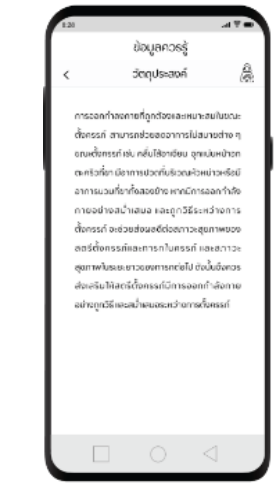

Objectives

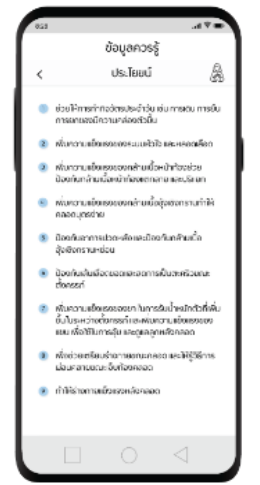

Benefit Gestational Age

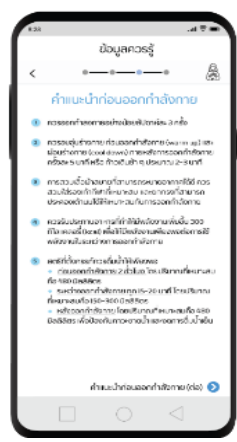

First trimester

Exercise posture

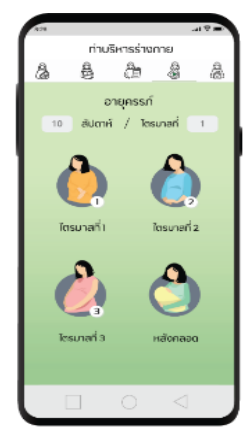

Cool Down

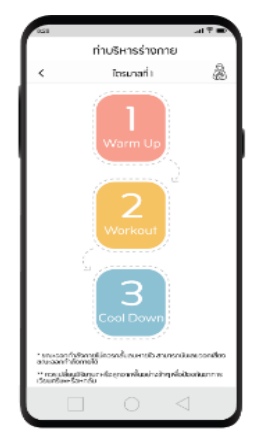

Exercise posture in the second

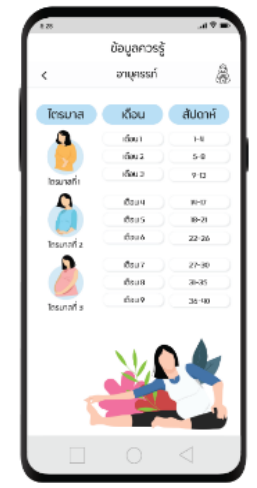

Selfassessment

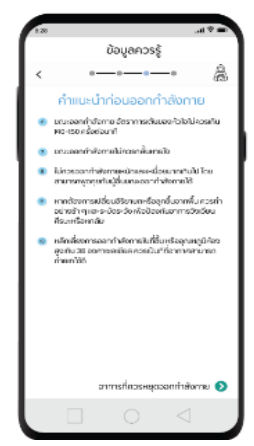

First trimester

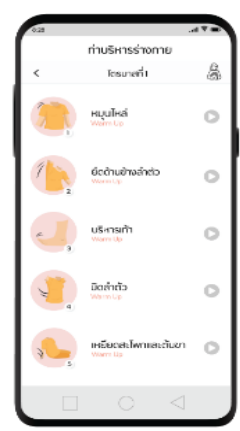

Warm Up

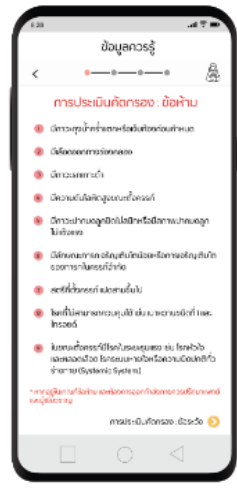

Prohibition

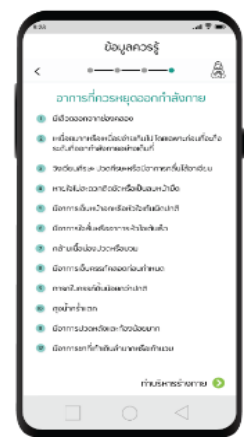

Workout

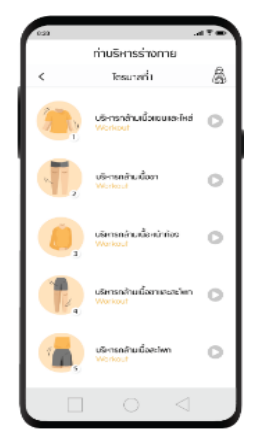

Workout 


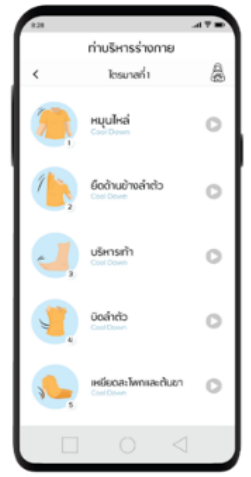

Cool Down

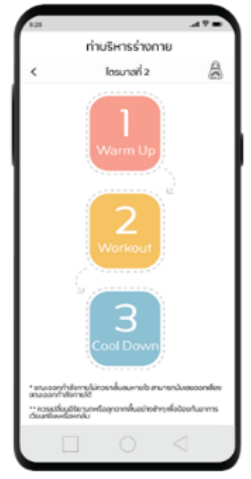

Third trimester

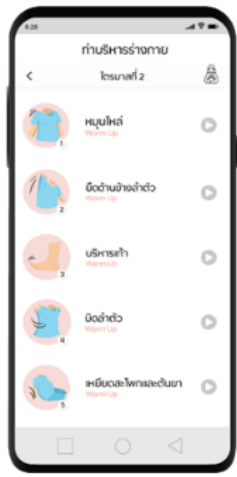

Strengthening exercise

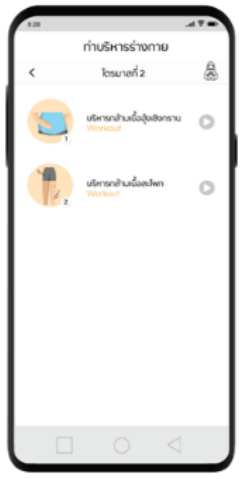

Breathing exercise

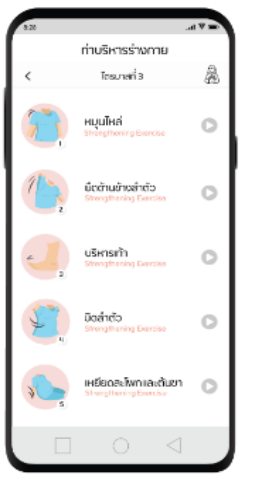

Recorder:

Calendar

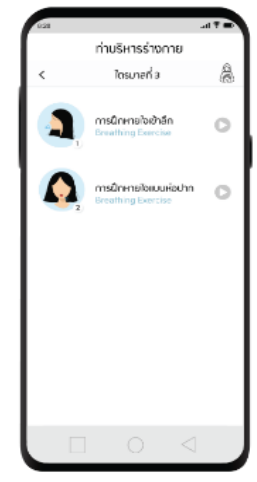

References display in a video tool
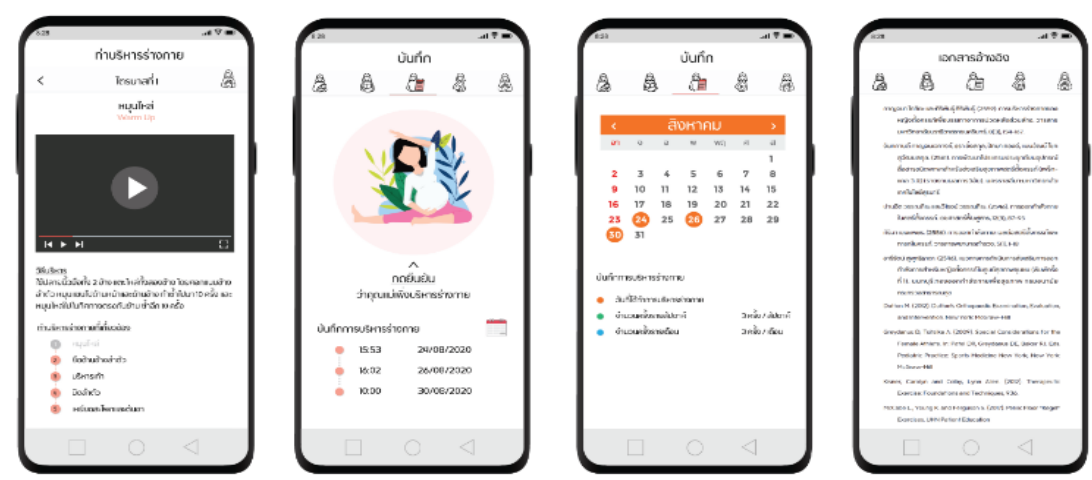

Fig 3. Prototype Application 


\subsection{Post-prototype process (Testing round one)}

Having developed the prototype, a questionnaire was constructed in order to determine users' level of satisfaction with three aspects, namely, perceived user interface, perceived ease of use, and reliability. The results of the evaluation are shown in Tables 3-5 based on means and standard deviation.

UI testing: The average score of satisfaction with the prototype's user interface shown in Table 3 was $4.12 \pm 0.073$. It should be noted that the participants perceived the UI in this application. Most of them liked the background or image pattern $(\overline{\mathrm{X}}=$ 4.687), as well as the number of menus and ease of use $(\overline{\mathrm{X}}=4.542)$ and the proportion of display and information $(\bar{X}=4.501)$. However, the score of Q4, Q6 and Q10 was lower than 4.0, which suggested that the aspects that needed to be improved in this application were that the image menu must be easy to understand (Q4), the font size should fit the screen (Q6) and the graphic layout and symbols should correspond and be easy to understand (Q10).

Table 3. Summary of results of user interface evaluation

\begin{tabular}{|c|c|c|c|c|c|c|}
\hline \multirow[b]{2}{*}{$\mathbf{Q}$} & \multirow[b]{2}{*}{ Assessment } & \multicolumn{3}{|c|}{ User feedback scales $(n=23)$} & \multirow[b]{2}{*}{ Avg } & \multirow[b]{2}{*}{ sd. } \\
\hline & & IT experts & \begin{tabular}{|c|} 
Physical \\
therapists
\end{tabular} & \begin{tabular}{|c|} 
Pregnant \\
users
\end{tabular} & & \\
\hline 1 & Screen buttons are easy to use & 4.00 & 3.80 & 4.20 & 4.072 & 0.496 \\
\hline 2 & $\begin{array}{l}\text { Foreground and background on screen are } \\
\text { clear }\end{array}$ & 4.33 & 4.40 & 4.20 & 4.258 & 0.594 \\
\hline 3 & Screen color is appropriate & 4.67 & 4.80 & 4.07 & 4.284 & 0.684 \\
\hline 4 & $\begin{array}{l}\text { Picture on menu enables user to understand the } \\
\text { usage }\end{array}$ & 3.67 & 3.40 & $3.53^{*}$ & 3.504 & 0.491 \\
\hline 5 & $\begin{array}{l}\text { The number of menus is appropriate, easy to } \\
\text { use }\end{array}$ & 4.33 & 4.60 & 4.53 & 4.542 & 0.491 \\
\hline 6 & $\begin{array}{l}\text { Font size is appropriate for the screen, easy to } \\
\text { read }\end{array}$ & 3.67 & 3.40 & $3.27 *$ & 3.319 & 0.623 \\
\hline 7 & Background or image pattern is appropriate & 4.33 & 4.80 & 4.67 & 4.687 & 0.472 \\
\hline 8 & $\begin{array}{l}\text { Proportion of display and information is appro- } \\
\text { priate }\end{array}$ & 4.33 & 4.80 & 4.40 & 4.501 & 0.494 \\
\hline 9 & Screen resolution is clear & 4.33 & 4.60 & 4.20 & 4.310 & 0.538 \\
\hline 10 & $\begin{array}{l}\text { Graphic layout and symbols are easy to under- } \\
\text { stand }\end{array}$ & 3.33 & 3.40 & $3.80 *$ & 3.675 & 0.473 \\
\hline & Total & & & & 4.115 & 0.535 \\
\hline
\end{tabular}

Usability testing: The average score of every question related to usability was at least 4.5, as shown in Table 4. This meant that the experts were satisfied with the perceived usability of the app and thought that most users would be able to understand its performance and become familiar with it. They liked the media function because it was easy to understand so that users could follow it. Therefore, the usability of various functions in the application did not need further modification. 
Table 4. Summary of results of usability evaluation

\begin{tabular}{|c|c|c|c|c|c|c|}
\hline \multirow[b]{2}{*}{$\mathbf{Q}$} & \multirow[b]{2}{*}{ Assessment } & \multicolumn{3}{|c|}{ User feedback scales $(n=23)$} & \multirow[b]{2}{*}{ Avg } & \multirow[b]{2}{*}{ sd. } \\
\hline & & IT experts & \begin{tabular}{|c|} 
Physical \\
therapists \\
\end{tabular} & \begin{tabular}{|c|} 
Pregnant \\
users
\end{tabular} & & \\
\hline 1 & $\begin{array}{l}\text { Application is easy to use. Users will understand } \\
\text { how to use it. }\end{array}$ & 4.67 & 4.80 & 4.80 & 4.794 & 0.404 \\
\hline 2 & Application provides useful information. & 4.33 & 4.80 & 4.73 & 4.733 & 0.457 \\
\hline 3 & Users can easily add or edit their information. & 5.00 & 4.80 & 4.80 & 4.809 & 0.373 \\
\hline 4 & $\begin{array}{l}\text { The media (video) function is easily followed } \\
\text { and easily understood. }\end{array}$ & 4.67 & 4.60 & 4.87 & 4.788 & 0.406 \\
\hline 5 & $\begin{array}{l}\text { The information providing function is satisfac- } \\
\text { tory. }\end{array}$ & 5.00 & 4.80 & 4.73 & 4.762 & 0.406 \\
\hline 6 & The personal recorder function is satisfactory. & 4.33 & 4.40 & 4.67 & 4.583 & 0.488 \\
\hline 7 & $\begin{array}{l}\text { The follow-up function for tracking the exercise } \\
\text { is satisfactory. }\end{array}$ & 5.00 & 4.80 & 4.73 & 4.762 & 0.406 \\
\hline 8 & $\begin{array}{l}\text { The calculation function for gestational age and } \\
\text { delivery is satisfactory }\end{array}$ & 4.67 & 4.80 & 4.6 & 4.655 & 0.467 \\
\hline \multicolumn{5}{|c|}{ Total } & 4.735 & 0.425 \\
\hline
\end{tabular}

Application reliability test: As shown in Table 5, the average score of the application's reliability was $4.402 \pm 0.65$. However, although the participants perceived that this application was reliable, the score for Q2 was lower than $4.5(\overline{\mathrm{X}}=4.232)$. This appeared to suggest that the accuracy and reliability of the information in the application (Q2) needed to be improved.

Table 5. Summary of results of application reliability evaluation

\begin{tabular}{|c|c|c|c|c|c|c|}
\hline \multirow[b]{2}{*}{$\mathbf{Q}$} & \multirow[b]{2}{*}{ Assessment } & \multicolumn{3}{|c|}{ User feedback scales $(\mathrm{n}=\mathbf{2 3})$} & \multirow[b]{2}{*}{ Avg } & \multirow[b]{2}{*}{ sd. } \\
\hline & & IT experts & \begin{tabular}{|c|} 
Physical \\
therapists
\end{tabular} & $\begin{array}{c}\text { Pregnant } \\
\text { users }\end{array}$ & & \\
\hline 1 & Users are confident in the application. & 4.00 & 4.60 & 4.53 & 4.528 & 0.577 \\
\hline 2 & $\begin{array}{l}\text { Users believe that the information provided in the } \\
\text { application is accurate. }\end{array}$ & 3.33 & 3.40 & 4.60 & 4.232 & 0.829 \\
\hline 3 & $\begin{array}{l}\text { Users are confident the recommendations provided } \\
\text { in the application that will not harm them. }\end{array}$ & 3.67 & 4.60 & 4.60 & 4.559 & 0.658 \\
\hline 4 & $\begin{array}{l}\text { Users accept the usage of the application and will } \\
\text { use it as instructional media for exercise. }\end{array}$ & 3.67 & 4.40 & 4.60 & 4.507 & 0.585 \\
\hline 5 & $\begin{array}{l}\text { Users believe that the application can reduce the } \\
\text { time to access various information. }\end{array}$ & 4.00 & 4.20 & 4.73 & 4.562 & 0.580 \\
\hline 6 & The application will facilitate users to exercise. & 3.67 & 4.80 & 4.80 & 4.751 & 0.584 \\
\hline 7 & Users will recommend the application to others. & 3.33 & 4.20 & 4.73 & 4.533 & 0.732 \\
\hline \multicolumn{5}{|c|}{ Total } & 4.524 & 0.649 \\
\hline
\end{tabular}

\subsection{Revised prototype (Testing round two)}

After the first prototype had been evaluated, the feedback from the physical therapists, IT experts and pregnant users was analysed in order to improve the user interface and reliability of the application. According to the UI test results, each menu of the 
previous version of the prototype contained many different images that did not go the same way, and the overall direction was inconsistent due to the use of various icons. Based on some suggestions, an image menu was added to the revised version in order to generate the highest usage efficiency, and the pattern of the icons was changed to make it consistent with the overall app to enhance users' satisfaction. In addition, the text display had been found to be too small, making it difficult to read; hence, the text in the revised version was fixed by increasing its size and enlarging the spacing between the lines. Moreover, since the symbols in the previous version were inaccurate and did not match the meaning of the graphic on the screen, they were replaced with new symbols, in order to enhance users' perception.

In the previous reliability test, the average score of the statement, "Users believe that the information provided in the application is accurate" was 4.38. Since this was lower than the criteria score of 4.5 , more references were added to the revised version of the app, including books, journal articles and research reports in national and international publications, so that users could access more information to support their physical activity, as well as other pregnancy-related data from credible sources.

Second round of evaluation: After developing the revised version, the questionnaire was applied to the same groups of participants in order to obtain their feedback of three aspects of the app, namely, the user interface, usability, and reliability.

The scores of each assessment of the revised version can be seen in Tables 6-8. The evaluation of the user interface in the second round is shown in Table 6, which indicates an increase of the average scores of Q4, Q6, and Q10. Moreover, the average scores of Q2, Q7, and Q9 had also increased, which meant that these improvements had enhanced users' satisfaction with the overall user interface, not just the corrected aspects.

Table 6. Summary of results of user interface evaluation (Second round)

\begin{tabular}{|c|c|c|c|c|c|c|}
\hline \multirow[b]{2}{*}{$\mathbf{Q}$} & \multirow[b]{2}{*}{ Assessment } & \multicolumn{3}{|c|}{ User feedback scales $(n=23)$} & \multirow[b]{2}{*}{ Avg } & \multirow[b]{2}{*}{ sd. } \\
\hline & & $\begin{array}{c}I T \\
\text { Experts }\end{array}$ & \begin{tabular}{|l|} 
Physical \\
therapists
\end{tabular} & \begin{tabular}{|c|}
$\begin{array}{c}\text { Pregnant } \\
\text { users }\end{array}$ \\
\end{tabular} & & \\
\hline 1 & Screen buttons are easy to use & 4.67 & 4.80 & 4.80 & 4.779 & 0.460 \\
\hline 2 & Foreground and background on screen are clear & 4.67 & 4.40 & 4.53 & 4.504 & 0.460 \\
\hline 3 & Screen color is appropriate & 4.67 & 4.80 & 4.07 & 4.284 & 0.460 \\
\hline 4 & Picture on menu enables user to understand the usage & 4.33 & 4.40 & 4.60 & 4.536 & 0.520 \\
\hline 5 & The number of menus is appropriate, easy to use & 4.33 & 4.60 & 4.53 & 4.542 & 0.350 \\
\hline 6 & Font size is appropriate for the screen, easy to read & 4.00 & 4.00 & 4.73 & 4.510 & 0.530 \\
\hline 7 & Background or image pattern is appropriate & 4.33 & 4.80 & 4.87 & 4.826 & 0.414 \\
\hline 8 & Proportion of display and information is appropriate & 4.33 & 4.80 & 4.40 & 4.501 & 0.494 \\
\hline 9 & Screen resolution is clear & 4.33 & 4.80 & 4.47 & 4.548 & 0.494 \\
\hline 10 & Graphic layout and symbols are easy to understand & 4.00 & 3.80 & 4.87 & 4.551 & 0.594 \\
\hline \multicolumn{5}{|c|}{ Total } & 4.558 & 0.477 \\
\hline
\end{tabular}

The results of the second round of the usability evaluation are illustrated in Table 7. Although the usability of the first version met the criteria and needed no modification in the further version, the average score of Q1, Q2, and Q4 increased in the second round. This indicated that users' satisfaction with the usability of the app increased with the improved interface design or reliability. 
Table 7. Summary of results of usability evaluation (second round)

\begin{tabular}{|c|c|c|c|c|c|c|}
\hline \multirow[b]{2}{*}{$\mathbf{Q}$} & \multirow[b]{2}{*}{ Assessment } & \multicolumn{3}{|c|}{ User feedback scales $(n=23)$} & \multirow[b]{2}{*}{ Avg } & \multirow[b]{2}{*}{ sd. } \\
\hline & & \begin{tabular}{|c|} 
IT \\
experts
\end{tabular} & \begin{tabular}{|c|} 
Physical \\
therapists
\end{tabular} & $\begin{array}{c}\begin{array}{c}\text { Pregnant } \\
\text { users }\end{array} \\
\end{array}$ & & \\
\hline 1 & $\begin{array}{l}\text { Application is easy to use. Users will understand how } \\
\text { to use it. }\end{array}$ & 5.00 & 5.00 & 4.80 & 4.861 & 0.332 \\
\hline 2 & Application provides useful information. & 4.67 & 4.80 & 4.80 & 4.794 & 0.404 \\
\hline 3 & Users can easily add or edit their information. & 5.00 & 4.80 & 4.80 & 4.809 & 0.373 \\
\hline 4 & $\begin{array}{l}\text { The media (video) function is easily followed and } \\
\text { easily understood. }\end{array}$ & 4.67 & 5.00 & 4.87 & 4.893 & 0.333 \\
\hline 5 & The information providing function is satisfactory. & 5.00 & 4.80 & 4.73 & 4.762 & 0.406 \\
\hline 6 & The personal recorder function is satisfactory. & 4.33 & 4.40 & 4.67 & 4.583 & 0.488 \\
\hline 7 & $\begin{array}{l}\text { The follow-up function for tracking the exercise is } \\
\text { satisfactory. }\end{array}$ & 5.00 & 4.80 & 4.73 & 4.762 & 0.406 \\
\hline 8 & $\begin{array}{l}\text { The calculation function for gestational age and } \\
\text { delivery is satisfactory }\end{array}$ & 4.67 & 4.80 & 4.6 & 4.655 & 0.467 \\
\hline \multicolumn{5}{|c|}{ Total } & 4.764 & 0.401 \\
\hline
\end{tabular}

The results of the second round of evaluating the reliability of the app are shown in Table 8. After improving the points of Q2, Q3 and Q7, the participants seemed to be increasingly satisfied with the point of fixing in the revised version, and users' confidence in the app and the information provided in it also increased.

Table 8. Summary of results of application reliability evaluation (Second round)

\begin{tabular}{|c|c|c|c|c|c|c|}
\hline \multirow[b]{2}{*}{$\mathbf{Q}$} & \multirow[b]{2}{*}{ Assessment } & \multicolumn{3}{|c|}{ User feedback scales $(\mathrm{n}=23)$} & \multirow[b]{2}{*}{ Avg } & \multirow[b]{2}{*}{ sd. } \\
\hline & & $\begin{array}{c}\text { IT } \\
\text { Experts }\end{array}$ & $\begin{array}{l}\text { Physical } \\
\text { therapists }\end{array}$ & $\begin{array}{c}\text { Pregnant } \\
\text { users }\end{array}$ & & \\
\hline 1 & Users are confident in the application. & 4.00 & 4.60 & 4.47 & 4.481 & 0.572 \\
\hline 2 & $\begin{array}{l}\text { Users believe that the information provided in the ap- } \\
\text { plication is accurate. }\end{array}$ & 3.67 & 4.00 & 4.60 & 4.403 & 0.700 \\
\hline 3 & $\begin{array}{l}\text { Users are confident the recommendations provided in } \\
\text { the application that will not harm them. }\end{array}$ & 4.33 & 4.80 & 4.73 & 4.733 & 0.540 \\
\hline 4 & $\begin{array}{l}\text { Users accept the usage of the application and will use } \\
\text { it as instructional media for exercise. }\end{array}$ & 3.67 & 4.40 & 4.60 & 4.507 & 0.585 \\
\hline 5 & $\begin{array}{l}\text { Users believe that the application can reduce the time } \\
\text { to access various information. }\end{array}$ & 4.00 & 4.20 & 4.73 & 4.562 & 0.580 \\
\hline 6 & The application will facilitate users to exercise. & 3.67 & 4.80 & 4.80 & 4.751 & 0.584 \\
\hline 7 & Users will recommend the application to others. & 4.00 & 4.40 & 4.80 & 4.661 & 0.572 \\
\hline \multicolumn{5}{|c|}{ Total } & 4.585 & 0.59 \\
\hline
\end{tabular}

It was observed from the second round of evaluation that the average scores of all aspects had increased from $4.115 \pm 0.535$ to $4.558 \pm 0.477$ (user interface), from 4.735 \pm 0.425 to $4.764 \pm 0.401$ (usability), and from $4.524 \pm 0.649$ to $4.585 \pm 0.59$ (application reliability). This indicated that the physical therapists and IT experts perceived that the revised version of the application design met their requirements, most notably in terms of the user interface, usability and reliability. 


\section{Discussion}

It is important for pregnant women and their baby to eat healthily, manage their weight and engage in physical activity. Observational studies of women who exercise during pregnancy have shown benefits such as a reduction of gestational diabetes mellitus, caesarean births and operative vaginal deliveries, as well as post-partum recovery time [48].

Although most pregnant women can receive health-related information and be motivated to change their behaviour by individual health professionals, it has been demonstrated by previous researchers that many of these women appear to be confused by the health information they are given in antenatal care [49]. This especially applies to physical activity and many pregnant women complain of the lack of access to consistent information, advice and support in relation to the great benefit of physical activity during pregnancy [26]. Therefore, they may appreciate a mobile application that can provide them with health information anytime and anywhere.

Health applications for pregnant women are ubiquitous and continue to be progressed. However, few of the current apps that purport to deliver pregnancy information perform well on a mobile platform and still fewer are available in the Thai language. This ineffective use of language greatly reduces their acceptance. [50] MoomMae is one of the few apps that support breastfeeding mothers in the Thai language and, as a result, it is more familiar and unique for Thai users than foreign apps [51]. Furthermore, most of the existing applications have been found to be problematic in terms of UI design, since most user interfaces are designed in English and are hence, incompatible with non-English speakers or people of a different culture. Hence, there is a need to generate a user interface that is familiar to locals to achieve the aim of developing an application for pregnant women in Thailand.

This study responded to this need with the design of a user interface for a pregnancyrelated app based on similar applications that are currently available to pregnant women in Thailand on an Android platform. Design thinking was applied as a methodology to identify and resolve the problems with the current application design. Consistency with previous researchers who recommended the use of the design thinking approach to identify the needs of culturally-sensitive groups for the development of mHealth technology resulted in reducing the gap between end-users and developers [52].

The involvement of pregnant women users in each step of the development process helped to identify users' interface preferences. It was critical to start with the needs of the intended end-users to design an application that they perceived to be easy to use and useful. If an mHealth app fails to meet end-users' needs, it will be misused or underutilised, leading to unmet health objectives and possible adverse results [53].

However, the credibility and validity of the application, such as the quality of the content and trustworthiness of the information sources, are the greatest concerns of endusers when they interact with an mHealth application [54-55]. In response to these concerns, the recommendations of physical therapists were used to design the prototype app in this study. These recommendations were deemed to be important for pregnant women who are using the application by themselves because they are related to safety in pregnancy. If the development process of a health application lacks professional 
medical involvement, its quality is likely to be subverted [56]. Incorporating the recommendations of health professionals in the process of development not only increases the confidence of pregnant women, but also of other health professionals as they demonstrate the application to their patients. [57]

Meanwhile, the recommendations of IT experts were also included in this study as part of the graphical user interface design and application's performance. The IT experts provided their perspective of a technique to develop the functional aspects of the app [58]. They suggested that the usability should be designed by focusing on the consistency between users and functions in respect of the menu design, symbols, appropriate colours and communication [42-43]. The feedback from the IT experts was particularly useful for integrating mobile technology and health information.

The research findings provided a design framework that could be used to improve the usability, content and graphical user interface of applications. The user interface was initially found to be the most frequently-reported problem area with the existing apps in the market, while content and usability problems were respectively reported later. The user interface is significant due to its effect on other elements of the application, such as its usability, while the content related to pregnant women is sensitive; hence, it must be accurate and reliable.

Furthermore, the physical activities in existing pregnancy applications are often described in text or pictures, which tends to make the guidelines confusing. Hence, it is important to use less text and a simple and clear design with graphics, photos and videos to provide high visibility and increase users' understanding [59-61].

The wireframe in this study was made as a low-fidelity prototype on paper, which made it easier to visualize the performance of such an application. This had the benefit of encouraging the physical therapists, IT experts and pregnant users to provide feedback related to the importance of the interface, functions, contents and tasks before the implementation of the definitive mobile application. Creating as many prototypes as necessary in response to design recommendations from the participants produced promising results [62]. Based on feedback about the low fidelity of the prototypes, a mockup prototype was created and released to the participants to be tested.

The majority of the participants approved the prototype design in the first round of testing, apart from the user interface and reliability of the app. The next version was revised based on their feedback and to correspond with the literature review and the taxonomy of design. As a result, in the second round of testing, the participants were increasingly satisfied with the points that had been corrected in the revised version, as well as with other criteria. Therefore, users' satisfaction seemed to increase with the improvement of the interface design or the reliability of the application. Hence, this process had resulted in the production of an app that could effectively serve pregnant women. Importantly, each iteration enabled meaningful improvements to be made in the development of the app [63]. 


\section{Conclusion}

A new health application to encourage pregnant women to safely engage in beneficial physical activity was produced in this study based on identifying the key problems of the current applications available in the market and outlining some possible solutions. Design thinking methodology was utilized to systematically determine the results and the outcome demonstrated the significance of applying a systematic analysis to develop an app that comprised media contents, content providers, user's information record, data tracking and information calculator. A prototype was produced based on the recommendations of pregnant women users, physical therapists and IT experts. This was subsequently tested to obtain feedback related to its user interface, usability and reliability.

The findings of this study can be said to constitute a design framework for improving the usability, content and graphical user interface of applications. The user interface was initially found to be the most frequently-reported problematic aspect of existing apps, while content and usability problems were respectively reported later. The user interface of an app is significant due to its effect on other elements, such as usability, and content related to pregnant women is sensitive; hence, it must be accurate and reliable.

\section{$7 \quad$ Acknowledgement}

This research work was partially supported by Chiang Mai University and with the collaboration of the research group of embedded systems and mobile applications in health science.

\section{$8 \quad$ References}

[1] Research2Guidance. mHealth App Developer Economics study. The Current Status and Trends of the mHealth App Market. 2017. Available from: www.research2guidance.com

[2] Thinnukool O, Khuwuthyakorn P, Wientong P. Pharmacy Assistant Mobile Application (PAMA): Development and reviews. International Journal of Interactive Mobile Technologies. 2017; 11(3):178-94.

[3] Nora A, Mohamed K, Ashraf M, Mowafa H. The prevalence and usage of mobile health applications among mental health patients in Saudi Arabia. Computer Methods and Programs in Biomedicine. 2018; 156:163-8.

[4] Carol C. Telehealth, Mobile Applications, and Wearable Devices are Expanding Cancer Care Beyond Walls. Seminars in Oncology Nursing. 2018; 34(2):118-125.

[5] Walter R, Sherry A.M. Mobile Alcohol Biosensors and Pharma-cotherapy Development Research. Alcohol. Available online 3 August. In Press, 2018.

[6] Lindsay R, Candice O, Donald K, and Shannon J. Apps and Mobile Health Technology in Rehabilitation the Good, the Bad, and the Unknown. Physical Medicine and Rehabilitation Clinics of North America. In press; 2019. 
[7] Lamyae S, Ali I, Leanne MR, Hassan A, Rachid B, JoséLuis. A. Mobile health applications for postnatal care: Review and analysis of functionalities and technical features. Computer Methods and Programs in Biomedicine. 2020; 184.

[8] Sahebjan T, Firoozeh M, Asiyeh P. Effect of a Mobile Application intervention on Knowledge, Attitude and Practice Related to Healthy Marriage among Youth in Iran. BMC Medical Informatics and Decision Making. 2020; 20:62.

[9] Markus P. 325,000 mobile health apps available in 2017 - Android now the leading mHealth platform. research2guidance. 2017. Retrieved from https://research2guidance.com/325000mobile-health-apps-available-in-2017/

[10] Malone N. C., Williams M. M., Smith Fawzi M. C., Bennet J., Hill C., Katz J. N., Oriol, N. E. Mobile health clinics in the United States. International journal for equity in health. 2020; 19(1):40 [doi.org/10.1186/s12939-020-1135-7]

[11] Molly M. Smartphone users in Thailand 2013-2022. Statista. 2019. Retrieved from: https://www.statista.com/statistics/467191/forecast-of-smartphone-users-in-thailand/.

[12] Matters. Thailand App Market Statistics in 2020. Data Source 42matters. 2020. Retrieved from https://42matters.com/thailand-app-market-statistics

[13] DataReportal. Digital Thailand Report 2019. Retrieved from https://www.bullvpn.com/en/ blog/detail/digital-thailand-2019

[14] Gurupur V. P., Wan, T. (2017). Challenges in implementing mHealth interventions: a technical perspective. mHealth. 2017; 3(32) [doi.org/10.21037/mhealth.2017.07.05]

[15] Nielsen J, Budiu R. Mobile usability. Berkeley, CA: New Riders. 2013.

[16] Nielsen J, Page L. Top 10 Application-Design Mistakes. World Leaders in Research-Based User Experience. 2019. Retrieved from Online: https://www.nngroup.com/articles/top-10application-design-mistakes/.

[17] Chaudhry B.M., Faust L., Chawla, N.V. From Design to Development to Evaluation of a Pregnancy App for Low-Income Women in a Community-Based Setting. MobileHCI '19. 2019

[18] Magrabi F, Habli I, Sujan M, et al. Why is it so difficult to govern mobile apps in healthcare? BMJ Health Care Inform. 2019; 26(1) [doi:10.1136/bmjhci-2019-100006]

[19] Van Velthoven MH, Smith J, Wells G, et al. Digital health APP development standards: a systematic review protocol. BMJ Open 2018; 8: e022969.

[20] [20] Molly E, Irena Gorski \& Khanjan Mehta. Leveraging design thinking to build sustainable mobile health systems. Journal of medical engineering \& technology. 2016; 40(78):422-30 [http://dx.doi.org/10.1080/03091902.2016.1218560]

[21] Irena G., Joshua T. B., Staci S, Molly E and Khanjan M. Value propositions of mHealth projects, Journal of Medical Engineering \& Technology. 2016; 40(7-8):400-21 [doi: 10.1080/03091902.2016.1213907]

[22] Ziema M, and Abdul W. Revised approach for the prediction of functional size of mobile application. Applied Computing and Informatics. In press; 2019.

[23] Debasmita S, Ardhendu M. User Interface Design Issues for Easy and Efficient Human Computer Interaction: An Explanatory Approach. International Journal of Computer Sciences and Engineering. 2015; 3(1):127-135.

[24] Smith W., Wadley G., Daly O., Webb M., Hughson J., Hajek J., Parker A., Woodward-Kron R., Story, D.A. Designing an app for pregnancy care for a culturally and linguistically diverse community. OZCHI '17. 2017.

[25] Willcox J. C., P. van der Pligt, K. Ball, S. A. Wilkinson, M. Lappas, E. A. Long Papers OzCHI 2017, Nov 28 - Dec 1, Brisbane, Australia Human - Nature 345 McCarthy, and K. J. Campbell, "Views of Women and Health Professionals on mHealth Lifestyle Interventions in Pregnancy: A Qualitative Investigation.," JMIR mHealth uHealth. 2015; 3(4):99. 
[26] Weir, Z., Bush, J., Robson, S.C. et al. Physical activity in pregnancy: a qualitative study of the beliefs of overweight and obese pregnant women. BMC Pregnancy Childbirth 2010; 10(18) [https://doi.org/10.1186/1471-2393-10-18]

[27] Floyd A, Sakellariou D. Healthcare access for refugee women with limited literacy: layers of disadvantage. Int J Equity Health 2017; 16(1):195. [doi:10.1186/s12939-017-0694-8]

[28] Shamsi Al, Almutairi H., Mashrafi A. G., and Kalbani T. Implications of Language Barriers for Healthcare: A Systematic Review. Oman medical journal, 2020; 35(2):122. [https://doi.org/10.5001/omj.2020.40]

[29] Stapleton H, Murphy R, Correa-Velez I, Steel M, Kildea S. Women from refugee backgrounds and their experiences of attending a specialist antenatal clinic. Narratives from an Australian setting. Women Birth 2013 Dec 26(4):260-266. [https://doi.org/10.1016/ j.wombi.2013.07.004]

[30] Nectec. Mobile application. National Electronics and Computer Technology Center. 2020; 35(2):122. Retrieved from https://www.nectec.or.th/innovation/innovation-mobile-application/.

[31] Tangcharoensathien, V., Witthayapipopsakul, W., Panichkriangkrai, W., Patcharanarumol, W., and Anne Mills. (2018). Health systems development in Thailand: a solid platform for successful implementation of universal health coverage. 2018 March; 391(10126):1205-23.

[32] Thomas, L. Design Thinking: Integrating Innovation, Customer Experience, and Brand Value. Allworth Press, New York, NY 10010. 2009.

[33] Martin R. The design of business. Harvard Business Press, Cambridge MA. 2009.

[34] David C.Chou (2018). Applying design thinking method to social entrepreneurship project. Computer Standards \& Interfaces 2018 January; 55:73-9.

[35] Brooks F.P. The design of design: essays from a computer scientist. Addison-Wesley Professional, NJ. 2010.

[36] Petersen, M., and Hempler, N.F. Development and testing of a mobile application to support diabetes self-management for people with newly diagnosed type 2 diabetes: a design thinking case study. BMC Med Inform Decis Mak. 2017; 17(133). [https://doi.org/10. 1186/s12911-017-0525-2]

[37] Anke Buhl, MarcSchmidt-Keilich, Viola Muster, Susanne Blazejewski, Ulf Schrader, Christoph Harrach, Martina Schäferc, and Elisabeth Süßbauer. Design thinking for sustainability: Why and how design thinking can foster sustainability-oriented innovation development. Journal of Cleaner Production 2019 September; 231:1248-57.

[38] Gerd Waloszek, Introduction to Design Thinking. 2012. Online: https://experience.sap.com/skillup/introduction-to-design-thinking/

[39] Interaction design foundation. Design Thinking.2018. Online: https://www.interaction-design.org/literature/topics/design-thinking.

[40] Nielsen J., -Usability inspection methods, $\|$ in Conf. Human factors in computing systems, Boston, Massachusetts, United States, 1994.

[41] British Standard. Design management systems - Managing inclusive design - Guide. 2005.

[42] Sheryl Burgstabler. Universal Design: Process, Principles, and Applications. University of Washington, Seattle, WA 98195-5670. 2015.

[43] Moyen M. M. A Study of Universal Design in Everyday Life of Elderly Adults. Procedia Computer Science. 2015; 67:57-66.

[44] Quinones D., and Rusu C. - How to develop usability heuristics: A systematic literature reviewll. Computer Standards \& Interfaces. 2017; 53:89-122.

[45] Pinem AA, Yeskafauzan A, Handayani PW, Azzahro F, Hidayanto AN, Ayuningtyas D. Designing a health referral mobile application for high-mobility end users in Indonesia. 
Heliyon. 2020 January; 6(1). [doi: 10.1016/j.heliyon.2020.e03174.] [PMID: 31938751; PMCID: PMC6953702.]

[46] Sutham, K., Khuwuthyakorn, P., \& Thinnukool, O. Thailand medical mobile application for patients triage base on criteria-based dispatch protocol. BMC medical informatics and decision making.2020; 20(1); 66. [https://doi.org/10.1186/s12911-020-1075-6]

[47] Shneiderman B, Plaisant C, Cohen M, Jacobs S, Elmqvist N. Designing the user interface: strategies for effective human-computer interaction. 6th ed. Boston: Pearson; 2016.

[48] Berghella V, Saccone G. Exercise in pregnancy! Am J Obstet Gynecol 2017; 216:335-7.

[49] Garnweidner, L.; Sverre Pettersen, K.; Mosdøl, A. Experiences with nutrition-related information during antenatal care of pregnant women of different ethnic backgrounds residing in the area of Oslo, Norway. Midwifery 2013; 29:130-7.

[50] mHIMSS app Usability Work Group. Amazon Web Services. 2012 Jul. Selecting a Mobile App: Evaluating the Usability of Medical Applications. http://s3.amazonaws.com/rdcmshimss/files/production/public/HIMSSguidetoappusabilityv1mHIMSS.pdf [accessed 202012-25]

[51] Wang CJ, Chaovalit P, Pongnumkul S. A Breastfeed-Promoting Mobile App Intervention: Usability and Usefulness Study. JMIR Mhealth Uhealth. 2018 Jan 26;6(1): e27. doi: 10.2196/mhealth.8337. PMID: 29374000; PMCID: PMC5807626.

[52] Hou IC, Lan MF, Shen SH, Tsai PY, Chang KJ, Tai HC, Tsai AJ, Chang P, Wang TF, Sheu SJ, Dykes PC. The Development of a Mobile Health App for Breast Cancer Self-Management Support in Taiwan: Design Thinking Approach. JMIR Mhealth Uhealth. 2020 Apr 30;8(4): e15780. doi: 10.2196/15780. PMID: 32352390; PMCID: PMC7226037.

[53] Maguire M. Methods to support human-centred design, International Journal of Humancomputer studies. 2001; 55(4):587-634.

[54] M. Goetz, M. Müller, L. Matthies et al., Perceptions of patient engagement applications during pregnancy: a qualitative assessment of the patient's perspective, JMIR Mhealth Uhealth 26 (5) (2017) e73.

[55] T. Krishnamurti, A. Davis, G. Wong-Parodi, B. Fischhoff, Y. Sadovsky, H. Simhan, Development and testing of the My Healthy Pregnancy App: a behavioural decision researchbased tool for assessing and communicating pregnancy risk, JMIR Mhealth Uhealth 10 (5) (2017) e42.

[56] Boulos, M.N.K.; Brewer, A.C.; Karimkhani, C.; Buller, D.B.; Dellavalle, R.P. Mobicle medical and health apps: State of the art, concerns, regulatory control and certification. J. Public Health Inform. 2014 [https://doi.org10.5210/ojphi.v5i3.4814.]

[57] S. Meedya et al., Developing and testing a mobile application for breastfeeding support: The Milky Way application, Women Birth (2020), https://doi.org/10.1016/j.wombi.2020.02.006.

[58] Stephen Watts. Application Developer Roles and Responsibilities. BMC Blogs. 2018. Online: https://www.bmc.com/blogs/application-developer-roles-responsibilities/

[59] Kentaro Toyama. Designing Mobile Interfaces for Novice and Low-Literacy Users. in ACM Transactions on Computer-Human Interaction 2011 April; 18(1):2 [https://doi.org/10.1145/1959022.1959024]

[60] Nielsen, J. Heuristic evaluation. In Nielsen, J., and Mack, R.L. (Eds.), Usability Inspection Methods. 1994. John Wiley \& Sons, New York, NY.

[61] Kai Tomboc. Text vs. Images: Which Content Format is Effective? Show, Don't Tell. Infographic Design and Data Visualization Blog. Easelly. 2019. Online: https://www.easel.ly/blog/text-vs-images-which-content-format-effective/

[62] Alma Chávez, Gilberto Borrego, J. Octavio Gutierrez-Garcia, Luis-Felipe Rodríguez, Design and evaluation of a mobile application for monitoring patients with Alzheimer's disease: 
A day center case study, International Journal of Medical Informatics, 2019,131:103972. https://doi.org/10.1016/j.ijmedinf.2019.103972.

[63] Farao J, Malila B, Conrad N, Mutsvangwa T, Rangaka MX, Douglas TS. A user-centred design framework for mHealth. PLoS One. 2020;15(8): e0237910. Published 2020 Aug 19. doi: 10.1371 /journal.pone.0237910.

\section{Authors}

Rachit Pinnarong and Sorawit Siangpipop, they are currently a student in Master of Knowledge and Innovation Management program in last year. He received his Bachelor of Science in Modern management and information technology from College of Arts, Media and Technology, Chiang Mai University. Email: Rachit.p@kic.camt.info, Sorawit.spp@gmail.com

Asst. Prof. Atichart Harncharnchai, Ph.D. After completing his master's degree, in the US, gaining tenure at New York Institute of Technology before returning to Thailand as at Technical Department of Thai Airway Int'. After that Dr. Atichart received his received Ph.D. in Knowledge Management from Chiang Mai University, Thailand in 2010. Email: Atichart.h@cmu.ac.th

Acrapol Nimmolrat, Ph.D. Dr. Acrapol got his Ph.D. in Knowledge and Innovation Management from Chiang Mai University in 2015. After he spent many years in US to study in program Business Administration from University of Missouri, Columbia in 1995. Currently, he works as lecturer in College of Arts, Media and Technology, Chiang Mai University. Email: Acrapol.n@cmu.ac.th

Asst. Prof. Orawit Thinnukool, Ph.D. After completing his Ph.D. in Research Methodology from Prince of Songkla University in 2014 with his lovey Professor McNeil from Statistics department at Macquarie University, Sydney. Dr. Orawit was promoted to assistant professor of Chiang Mai University in Technology management in 2019.

He now spends a lot of his lifetime to research in the medical innovation system. Email: Orawit.t@cmu.ac.th

Article submitted 2021-04-01. Resubmitted 2021-05-06. Final acceptance 2021-05-08. Final version published as submitted by the authors. 